\title{
Floodwater detection in urban areas using Sentinel-1 and WorldDEM data
}

\author{
David C. Mason $\odot,{ }^{\mathrm{a}, *}$ Sarah L. Dance $\odot,{ }^{\mathrm{b}, \mathrm{c}}$ and Hannah L. Cloke $\odot^{\mathrm{a}, \mathrm{b}, \mathrm{d}, \mathrm{e}}$ \\ ${ }^{a}$ University of Reading, Department of Geography and Environmental Science, Reading, \\ United Kingdom \\ ${ }^{b}$ University of Reading, Department of Meteorology, Reading, United Kingdom \\ ${ }^{\mathrm{c}}$ University of Reading, Department of Mathematics and Statistics, Reading, United Kingdom \\ ${ }^{\mathrm{d}}$ Uppsala University, Department of Earth Sciences, Uppsala, Sweden \\ ${ }^{\mathrm{e}}$ Centre for Natural Hazards and Disaster Science, Uppsala, Sweden
}

\begin{abstract}
Remote sensing using synthetic aperture radar (SAR) is an important tool for emergency flood incident management. At present, operational services are mainly aimed at flood mapping in rural areas, as mapping in urban areas is hampered by the complicated backscattering mechanisms occurring there. A method for detecting flooding at high resolution in urban areas that may contain dense housing is presented. This largely uses remotely sensed data sets that are readily available on a global basis, including open-access Sentinel-1 SAR data, the WorldDEM digital surface model (DSM), and open-access World Settlement Footprint data to identify urban areas. The method is a change detection technique that locally estimates flood levels in urban areas. It searches for increased SAR backscatter in the post-flood image due to double scattering between water (rather than unflooded ground) and adjacent buildings, and reduced SAR backscatter in areas away from high slopes. Areas of urban flooding are detected by comparing an interpolated flood level surface to the DSM. The method was tested on two flood events that occurred in the UK during the storms of Winter 2019-2020. High urban flood detection accuracies were achieved for the event in moderate density housing. The accuracy was reduced for the event in dense housing, when street widths became comparable to the DSM resolution, though it would still be useful for incident management. The method has potential for operational use for detecting urban flooding in near real-time on a global basis. (C) The Authors. Published by SPIE under a Creative Commons Attribution 4.0 Unported License. Distribution or reproduction of this work in whole or in part requires full attribution of the original publication, including its DOI. [DOI: 10.1117/1.JRS.15.032003]
\end{abstract}

Keywords: flood incident management; hydrology; synthetic aperture radar.

Paper 200737SS received Oct. 14, 2020; accepted for publication Jan. 12, 2021; published online Feb. 23, 2021.

\section{Introduction}

Flooding is responsible for a significant amount of human misery all over the world every year, causing death, injury, homelessness, displacement, and economic loss. ${ }^{1}$ The ten costliest floods that occurred between 1980 and 2014 caused the deaths of over 13,000 people and an estimated $\$ 187$ billion in economic losses. ${ }^{2}$ The risks to people and the economic impacts of flooding are most severe for urban flooding. The number of floods and the number of properties affected by them are likely to increase in the future due to the impact of climate change and the growing population exposure in floodplains. ${ }^{3}$

Flood detection is now commonly performed by high-resolution (HR) synthetic aperture radar (SAR) sensors. These sensors are able to penetrate the cloud that is often present during flooding, and to image at night time and during the day. Floodwater generally appears dark in an SAR image due to specular reflection from the water surface away from the antenna, provided that there is no significant surface water turbulence caused by wind, rain, or currents. There now exist several very high-resolution (VHR) SARs with spatial resolutions as high as $3 \mathrm{~m}$ or better that are capable of detecting urban flooding, including TerraSAR-X, ALOS-2/PALSAR-2, and

*Address all correspondence to David C. Mason, d.c.mason@ reading.ac.uk 
the COSMO-SkyMed, RADARSAT-2, and ICEYE constellations. Most recently, the HR Sentinel-1 (S-1) constellation has been launched, providing open access satellite data in near real-time acquired according to a preplanned schedule, making it very attractive for flood studies. The user is provided with processed multilook georegistered SAR images about $1 \mathrm{~h}$ after image reception at the ground station. ${ }^{4}$

If the SAR image can be obtained in near real-time, an important use of the flood extent is as a tool for operational flood incident management. ${ }^{5} \mathrm{~A}$ second use is to provide near real-time data for assimilation into urban flood inundation models, to correct the model state, and improve estimates of the model parameters and external forcing. ${ }^{6-13}$

A substantial amount of research has been carried out on automated flood detection in rural areas. ${ }^{14-30}$ Several organisations, including the Copernicus Emergency Management Service (EMS), have developed semi-automatic systems to extract the flood extent from an SAR image. These systems tend to work well in rural areas, but poorly in urban areas. A difficulty of urban flood detection using SAR is that because SAR is a side-looking instrument, substantial areas of urban ground surface may not be visible to the SAR due to radar shadowing and layover caused by buildings. Shadow will appear dark, similar to most water, so may be misclassified as water if the ground in shadow is dry. Layover will generally appear bright, possibly leading to misclassification of flooded ground as unflooded. The urban area that may be flooded but not visible to the SAR may be significant (e.g., 39\% in the study of Ref. 31). Further difficulties are that unflooded roads and tarmac areas can exhibit low backscatter similar to water, and that the image may be confused by double scattering signals between ground surfaces and adjacent buildings.

Due to these difficulties, the problem of urban flood detection using SAR has received less attention than its rural counterpart. However, a number of studies have now been made using a variety of techniques, including analysis of the backscatter intensities in a post-flood SAR image, ${ }^{32-36}$ change in backscatter intensities between pre- and postflood SAR images, ${ }^{23}$ use of coherence and backscatter intensities using pre- and postflood SAR images, ${ }^{4,37-39}$ and time-series analysis of SAR images. ${ }^{40}$

A number of methods of detecting urban flooding have been developed using VHR SAR data and LiDAR digital surface models (DSMs) of high spatial and height accuracy. Mason et al. ${ }^{32,33}$ used an SAR simulator in conjunction with LiDAR data of the urban area to predict areas of radar shadow and layover in the image caused by buildings and taller vegetation. The method detected flooding in urban areas that were not in shadow or layover by analyzing the backscattered intensities from a VHR SAR image acquired during the flooding. In Ref. 35, flooding detected in these areas was then propagated into areas of adjacent shadow and layover irrespective of their backscatter provided they were of similar elevation to the flooded areas. Tanguy et al. ${ }^{36}$ mapped river flooding in urban areas using VHR RADARSAT-2 backscatter intensities and flood return period (FRP) data produced by a hydrodynamic model. The flood level was estimated in rural areas using a postflood SAR image, and this rural flood level was used in conjunction with the FRP data to calculate where the flooding should be in the adjacent urban areas. Difficulties with these methods include the facts that VHR SAR data are rarely open access, and that their reliance on LiDAR limit their use to urban regions of the globe that have been mapped by airborne LiDAR.

An urban flood detection method would obviously become more useful if it was based on global data sets that could be accessed rapidly in an emergency. S-1 SAR is a suitable candidate because of its high resolution [20 $\mathrm{m}$ in normal interferometric wide (IW) swath mode], its short repeat time (six days at equator, less at higher latitudes), the increased coverage of floods it provides globally using its wide swath ( $240 \mathrm{~km}$ in IW mode), the availability of georeferenced images in near real time, its preplanned acquisition capability, and its open access.

Several methods have been developed using S-1 SAR that require only post- and preflood imagery, so that a rapid assessment of the urban flooding may be made. A two-stage approach was adopted in Ref. 38. The urban area was first detected using the fact that flooded buildings aligned roughly with the satellite flight direction will cause strong double-bounce SAR returns. ${ }^{34,41}$ Second, the change in interferometric coherence between pre- and postflood SAR images was used to refine the urban flooding determined using SAR intensity. An urban area that is not flooded should often have high coherence, whereas if there is flooding the coherence should be low. The method was tested with good results using S-1 data of Hurricane Harvey 
in Houston, Texas, in 2017. Li et al. ${ }^{4}$ employed an unsupervised classification method for flood detection in urban areas by synergistically using SAR intensity and interferometric coherence in a Bayesian network fusion framework. Using S-1 data of Hurricane Harvey and other SAR data, it was demonstrated that coherence provides valuable information in addition to intensity in urban flood mapping. (It should also be mentioned that, for the same flood, Ref. 39 used VHR TerraSAR-X intensity and coherence information to perform urban flood mapping with an active self-learning neural network.) Lin et al. ${ }^{40}$ also used time series observations of S-1 intensities at pixels of different cover types to perform urban flood detection in North Carolina due to Hurricane Matthew in 2016. Their pixel-based approach showed improved urban flood detection compared to using global thresholding on log intensity ratios from post- and preflood images.

The studies of Refs. 38 and 4 using S-1 data on the Houston flood definitely improved urban flood detection in low density suburban detached housing [10 houses per hectare ( 1 house per $\left.33 \times 33 \mathrm{~m}^{2}\right)$ ]. But many existing towns have higher densities than this. New estates now being built in England have 75 houses per hectare $\left(1\right.$ house per $11 \times 11 \mathrm{~m}^{2}$, though obviously there will be parks and squares to break the estates up). At the more extreme end of the scale, the Dharavi district of Mumbai, India, has a density of 630 dwellings per hectare. The methods developed for the Houston flood may be best suited to lower density urban environments. In narrow streets parallel to the satellite track (possibly with high buildings), the lower resolution of S-1 compared with VHR SAR means that a single S-1 pixel's backscatter may contain contributions from double scattering, shadow and layover, and from normal single scattering. In higher density housing, measures of SAR intensity and coherence may, therefore, be mixtures from several sources, especially as coherence measurement involves a resolution-reducing windowing operation over many pixels.

The uniqueness of the method presented here is that it builds on those above and uses S-1 intensity data to detect flooding at high resolution in urban areas that may contain dense housing. It is designed to work in mixed areas containing both urban regions and rural regions adjacent to them, as well as in urban areas alone. It largely uses global data sets that are readily available in an emergency. The design considerations underlying it are described below.

\section{Design Considerations}

In common with other techniques used for urban flood detection using S-1 imagery, the method is a change detection one using pre- and postflood single-polarization S-1 imagery.

In any domain containing urban areas, there may be dense housing in some parts, but this may be interspersed with more rural areas in others. Rural flooded areas containing submerged vegetation will often have a reduced SAR backscatter in the postflood image compared to the preflood image, due to specular reflection away from the sensor in the postflood image. This effect can be used to identify flood regions (see e.g., Refs. 33, 42, and 43). Water level observations (WLOs) may be obtained at the boundaries of the flood regions by intersecting them with a DSM.

In contrast, in dense urban areas, the above situation often tends to reverse because there is higher postflood than preflood backscatter due to the double scattering that occurs between flooded roads and adjacent building walls. The effect is particularly apparent in roads that are roughly parallel to the satellite direction of travel, which is precisely where backscatter due to flooding may be obscured due to the presence of radar shadow and layover. Provided a building is appropriately oriented and only flooded to a small depth, backscatter due to the double scattering from sensor to road to wall to sensor (or vice versa) is generally stronger than if the road is not flooded (when the road backscatter is from asphalt) (see below). The double scattering is evident as a bright line or curve at the ground range corresponding to that of the base of the wall. $^{44}$

Figure 1 shows how radar returns from different parts of a building and adjacent road are mapped into the slant range of an SAR image due to the fact that they reach the receiver at different times. As discussed in Ref. 34, proceeding from near to far slant range at constant azimuth, a bright stripe corresponding to the superposition of backscatter from the ground, wall, 


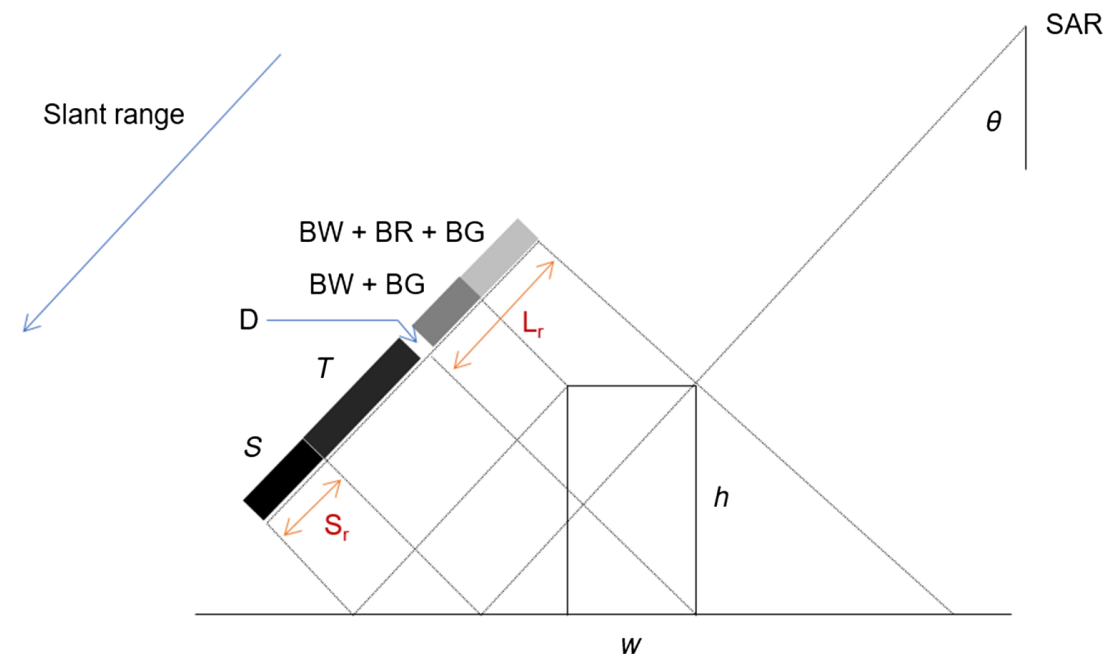

Fig. 1 Composition of different contributions in the SAR slant range (after Ref. 44). BW = Backscattering from wall, $T=$ Triple scattering, $B R=$ Backscattering from roof, $L_{r}=$ Slant range size of layover, BG = Backscattering from ground, $S_{r}=$ Slant range size of shadow, $\mathrm{D}=$ Double scattering, $\mathrm{S}=$ Shadow, $h=$ Building height, $w=$ Building width.

and roof (i.e., to layover) is first found. This is followed by a (usually) brighter return corresponding to wall-ground and ground-wall double scattering. The high intensity of this return is partly due to the fact that the double scattering ray paths all have the same length, corresponding to the range of the base of the wall. ${ }^{44} \mathrm{Next}$, there may be a dark area corresponding to higherorder multiple (e.g., triple) scattering (usually negligible compared to the other contributions), and finally, a still darker area corresponding to building shadow. When mapped into the twodimensional (2D) ground range-azimuth image, the shape of the double reflection return follows that of the ground-wall intersection, namely, a curve which in urban areas are often quasi-linear.

Mason et al. ${ }^{34}$ referred to Ref. 45 , which developed a simple model of double scattering from wall-ground structures using a physical optics approximation. The angular variables in their model are the incidence angle $\theta$ and the aspect angle $\varphi$, where $\varphi$ is the angle that the intersection line of the wall and road makes with the SAR direction of travel, with $\varphi=0$ deg when this line is parallel to the direction of travel. Using their model, assuming $\theta=30 \mathrm{deg}, \varphi=0 \mathrm{deg}$, and standard values for the complex dielectric constants of water and asphalt, it can be deduced that the ratio of the backscattering cross-section of wall-water to that of wall-asphalt in HorizontalHorizontal $(\mathrm{HH})$ polarization is $12 \mathrm{~dB}$. This is primarily because the permittivity of water is higher than that of asphalt (see Table 1 of Ref. 34). It can be difficult to distinguish asphalt surfaces from flooded roads on the basis of intensity from single scattering (see e.g., Ref. 40), but this comparison is simplified using double scattering. The model also shows that

Table 1 S-1 IW images used for flood detection.

\begin{tabular}{|c|c|c|c|c|c|c|}
\hline Site & $\begin{array}{l}\text { Flood image } \\
\text { acquisition } \\
\text { time (UTC) }\end{array}$ & $\begin{array}{l}\text { Reference image } \\
\text { acquisition } \\
\text { time (UTC) }\end{array}$ & Pass & $\begin{array}{l}\text { Resolution } \\
\text { (m) }\end{array}$ & $\begin{array}{l}\text { Local } \\
\text { incidence } \\
\text { angle } \\
\text { (degrees) }\end{array}$ & Polarisation \\
\hline \multirow{2}{*}{$\begin{array}{l}\text { Fishlake } \\
\left(53^{\circ} 36^{\prime} 47^{\prime \prime} \mathrm{N},\right. \\
\left.01^{\circ} 00^{\prime} 42^{\prime \prime W}\right)\end{array}$} & $\begin{array}{c}\text { November } 11 \\
2019,17: 49\end{array}$ & $\begin{array}{l}\text { October 18, } \\
2019,17: 49\end{array}$ & Ascending & 20 & 38 & VV \\
\hline & $\begin{array}{c}\text { November } 14 \\
2019,06: 14\end{array}$ & $\begin{array}{c}\text { September } 15 \\
2019,06: 14\end{array}$ & Descending & 20 & 42 & VV \\
\hline $\begin{array}{l}\text { Pontypridd } \\
\left(51^{\circ} 36^{\prime} 01^{\prime \prime} \mathrm{N},\right. \\
\left.3^{\circ} 20^{\prime} 42^{\prime \prime} \mathrm{W}\right)\end{array}$ & $\begin{array}{l}\text { February } 16, \\
2020,06: 31\end{array}$ & $\begin{array}{l}\text { February 04, } \\
2020,06: 31\end{array}$ & Descending & 20 & 34 & VV \\
\hline
\end{tabular}


the double scattering cross-section $\sigma_{\mathrm{HH}}$ decreases rapidly as $\varphi$ is increased (proportional to $\cos ^{8} \varphi$ ), so that if $\varphi=30 \mathrm{deg}, \sigma_{\mathrm{HH}}$ is only about $30 \%$ of that at $\varphi=0 \mathrm{deg}$.

Mason et al. ${ }^{34}$ also summarized Ref. 41, which used double scattering to develop a method of local flooding level estimation in urban areas using VHR SAR images. They used the rationale developed in Ref. 46 to associate the building wall height $h$ above the ground or water surface to the contribution of the double scattering to the radar cross-section $\sigma^{0}$

$$
\sigma^{0}=h f(\mathbf{p}),
$$

where $\mathbf{p}$ is a vector of known parameters, $\mathbf{p}=\left(l, \sigma, L, \varepsilon_{w}, \varepsilon_{s}, \theta, \varphi\right)$. Here, $l$ is the building length, $\sigma$ and $L$ are the standard deviation and the correlation length of the stochastic process, respectively, representing the ground surface, $\varepsilon_{w}$ is the complex dielectric constant of the building wall, and $\varepsilon_{s}$ is the complex dielectric constant of the ground surface. The function $f(\mathbf{p})$ was calculated using the GO-GO method in Ref. 46.

In the current study, both preflood and a postflood images are acquired. The ratio of the calculated double scattering cross-section assuming a water surface $\left(\sigma^{0}{ }_{w}\right)$ in the postflood image to that assuming a ground surface $\left(\sigma_{g}^{0}\right)$ in the preflood image is given as

$$
\sigma^{0}{ }_{w} / \sigma_{g}^{0}=\left(h_{A}-h_{W}\right) f\left(\mathbf{p}_{w}\right) /\left[\left(h_{A}-h_{G}\right) f\left(\mathbf{p}_{g}\right)\right],
$$

where $h_{A}$ is the building wall height, $h_{W}$ is the height of the floodwater, $h_{G}$ is the ground height, and $\mathbf{p}_{w}\left(\mathbf{p}_{g}\right)$ is $\mathbf{p}$ for water (ground). Iervolino et al. ${ }^{41}$ developed the TIArA method to estimate floodwater depth from Eq. (2) using a pair of post- and preflood images, and details are given there. However, observations on the flood events used in our study indicated that the crosssection ratios were significantly less than those obtained in Refs. 41 and 34, even for small values of $\varphi$ and small flooding depths. This is likely to be because the double scattering signal over water is being diluted due to the 10-m size of the S-1 pixel compared with VHR SAR. We concluded that the method of Ref. 41 was unlikely to be sensitive enough to estimate water depth using S- 1 .

However, if the height of the floodwater is approximately known and its depth is small compared to the building heights, it is possible to use Eq. (2) to ask the simpler question of whether the ground around a correctly oriented building is flooded or not. ${ }^{34}$ If the depth of flooding is small, Eq. (2) reduces to

$$
\sigma^{0}{ }_{w} / \sigma_{g}^{0} \approx f\left(\mathbf{p}_{w}\right) / f\left(\mathbf{p}_{g}\right) .
$$

If the ground is flooded, from Eq. (3), $\sigma^{0}{ }_{w} / \sigma_{g}^{0} \gg 1$, whereas if it is unflooded, the ratio should be 1 . Even though the ratio for a flooded building may be reduced due to the size of the S-1 pixel, it should still be $>1$.

This mechanism can be used to roughly find a flood boundary in the urban area and estimate urban WLOs on either side of it. Within most urban areas there will generally be a set of building edges in the correct orientation range. The double scatterers may be localized with high spatial resolution, since only adjacent S-1 pixels need to be examined. There is little point in pursuing a solution using shadow/layover maps (e.g., as in Ref. 33), as there is insufficient resolution in S-1 images.

Due to the size of the S-1 pixel and inaccuracies in the DSM, it is inevitable that the individual water levels determined will be noisy, so the method finds the average rural WLO and average urban WLO in a local area and combines these. An average WLO surface is interpolated over the complete domain. Flooding is identified where the DSM is lower than the WLO surface. The simple hydrological constraint that water will occupy the lowest parts of the domain available to it is assumed.

The method requires the ready availability of a global DSM rather than LiDAR data, as the latter are only available on a local or regional basis. A suitable candidate with resolution similar to $\mathrm{S}-1$ is the WorldDEM DSM developed from the TanDEM-X mission. This has a spatial resolution of $12 \mathrm{~m}$ and a height accuracy of $1.4 \mathrm{~m}$ averaged over all cover types. ${ }^{47}$ Disadvantages of the WorldDEM DSM are that it is not open access and that it may be challenging to rapidly purchase data from it in the event of a flood. There are open access global DSMs freely available, 
such as the Shuttle Radar Topography Mission or the Advanced Spaceborne Thermal Emission and Reflection Radiometer. ${ }^{48}$ However, these have large height errors and poor spatial resolution compared to WorldDEM. In fact, use of a high-resolution global DSM such as WorldDEM is essential to the method, as it requires edge detection in a DSM of similar resolution to the S-1 data (see Sec. 4.2).

To identify urban areas, the World Settlement Footprint (WSF) 2015 10-m resolution data can be used. ${ }^{49}$ These data have been derived from a very large number of S-1 radar images and Landsat- 8 optical images acquired during 2014-2015. The WSF global urban binary mask has been shown to have an accuracy of $86 \%$, and to be more accurate than masks obtained using other data. ${ }^{49}$ The WSF mask is freely available on European Space Agency (ESA) Urban Thematic Exploitation Platform.

A disadvantage is that urban flood detection using double scattering cannot easily identify fine structure in the flooding in the urban area. As a result, there may be, for example, urban areas that are protected by embankments yet below the estimated flood level. If FRP maps are available, they can be used to modify the DSM, if necessary, in a preprocessing operation, and effectively assign high return periods to such areas. ${ }^{36}$

Prior to describing the method in detail, the flood events on which it was tested are introduced to allow these to illustrate stages of the method during its description.

\section{Study Events and Data Sets}

Between November 2019 and February 2020, severe winter flooding occurred across the UK. The first wave of flooding occurred in November 2019, and mainly affected the north and west of England. Further isolated flooding incidents were reported in December and January, before the second main wave of flooding, caused by Storms Ciara and Dennis, occurred in February 2020. The excessive rainfall led to the wettest February since records began.

Two urban flood events from this period were studied, the Fishlake flood of November 8, 2019, to November 20, and the Pontypridd flood of February 15, 2020, to February 16, 2020, (Fig. 2) Although the urban flood detection method proposed is global, an advantage of using UK events is that aerial photos and Environment Agency (EA) LiDAR data can be obtained to validate results, as well as EA flood risk maps.

\subsection{Fishlake Flood of 8-20 November 2019}

Fishlake is a village in Yorkshire, England, near the river Don east and downstream of Doncaster. It was originally a fishing village on the Don (now diverted to the south). It has a population of 700 and is surrounded by farmland. Some parts of Fishlake have high housing density (30 houses/hectare), though the average density over the whole village is 15 houses/hectare.

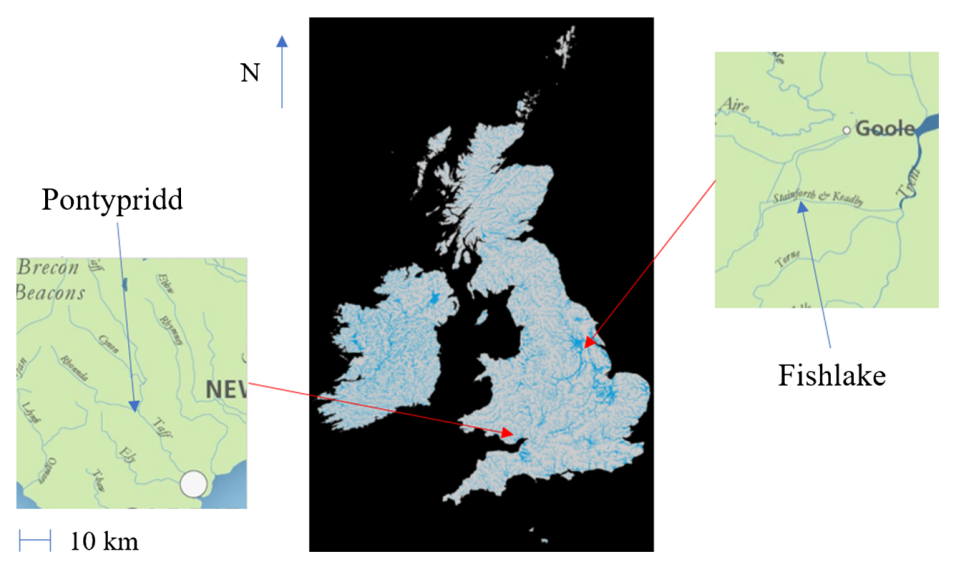

Fig. 2 Location of study sites in England and Wales. 


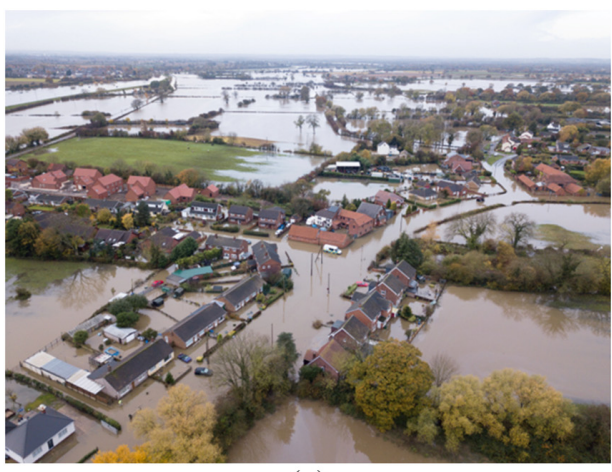

(a)

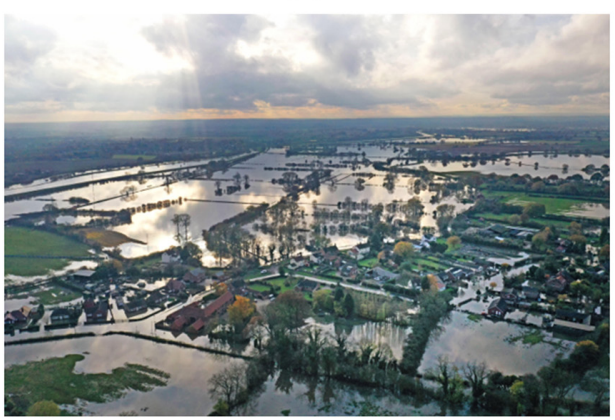

(b)

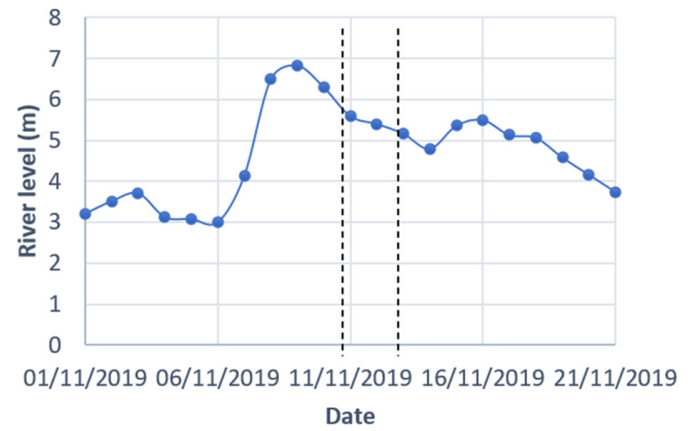

(c)

Fig. 3 (a) Flooding in Fishlake on November 11, 2019, looking from E (OSWNS); (b) flooding on November 14, 2019, from NE (OPA); and (c) levels for river Don at Fishlake (Ref. 51, vertical dashed lines mark overpass times).

The flooding was caused by an extreme weather event due to an area of low pressure stalling over the north of England. The river Don and its tributary burst their banks into an area that was already heavily sodden from rain over a period of weeks. More than 1000 homes from the village and surrounding area had to be evacuated, leaving many residents homeless for days. ${ }^{50}$ According to the EA flood risk map, the area flooded has a low risk of flooding with an annual exceedance probability (AEP) between $0.1 \%$ and $1 \%$, as the river Don is constrained within $7-\mathrm{m}$ high flood barriers as it flows past Fishlake. The flooding was imaged by S-1 on November 11, 2019, and November 14, 2019 (Table 1). There was little flooding on the image of November 08, 2019.

A number of aerial photos showing the urban flooding were available for validation [e.g., Figs. 3(a) and 3(b)]. The flood hydrograph is shown in Fig. 3(c) and indicates that the SAR images were obtained on the falling limb.

\subsection{Pontypridd Flood of 15-16 February 2020}

Pontypridd is a former coal-mining town to the north of Cardiff on the river Taff in Wales, with narrow streets and dense Victorian terraced housing. It has a population of 33,000 and sits in a steep-sided valley, at the confluence of the Taff and its tributary the Rhondda. In the east of the old town next to the river Taff, the housing density is 75 houses/hectare. More than 1000 homes and businesses were damaged after rivers flooded when Storm Dennis hit communities in south and mid-Wales on February 15, 2020, to February 16, 2020. The storm was classed as a weather bomb due to the large drop in pressure associated with it. The center of Pontypridd was extensively affected after the river Taff flooded [Figs. 4(a) and 4(b)]. ${ }^{52}$ From the Natural Resources Wales flood risk map, the area flooded has a low risk of flooding, with an AEP between $0.1 \%$ and $1 \%$. Although the duration of the flooding was not long, an S-limage was acquired at 6.31 am on February 16, 2020 (Table 1), only an hour or so after the flood peak, which, coupled with the fact that validation photos were taken the same morning, make this an ideal data set for study. The flood hydrograph is shown in Fig. 4(c). 


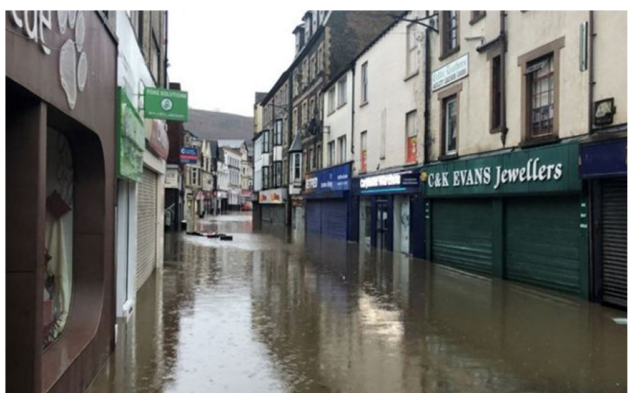

(a)

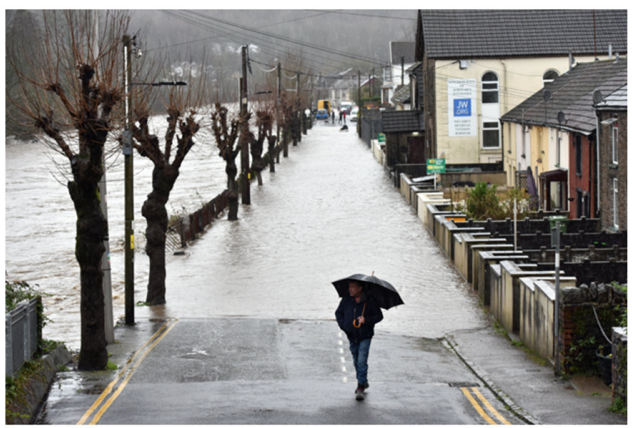

(b)

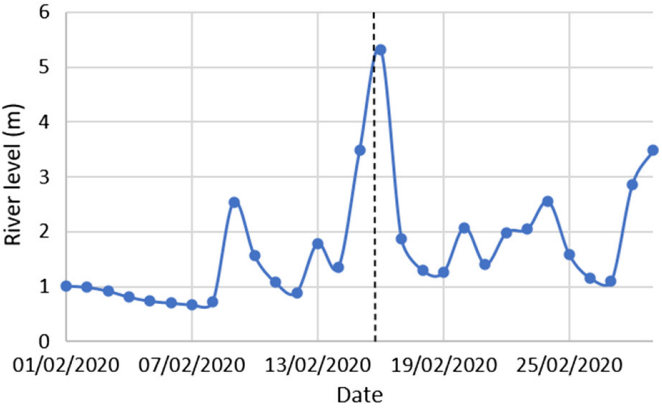

(c)

Fig. 4 (a) Flooding in Taff Street, Pontypridd town center (@ BBC News); (b) flooding in Sion Street adjacent to river (@ Richard Swingler); (c) levels for river Taff at Pontypridd (Ref. 51, vertical dashed line marks overpass time).

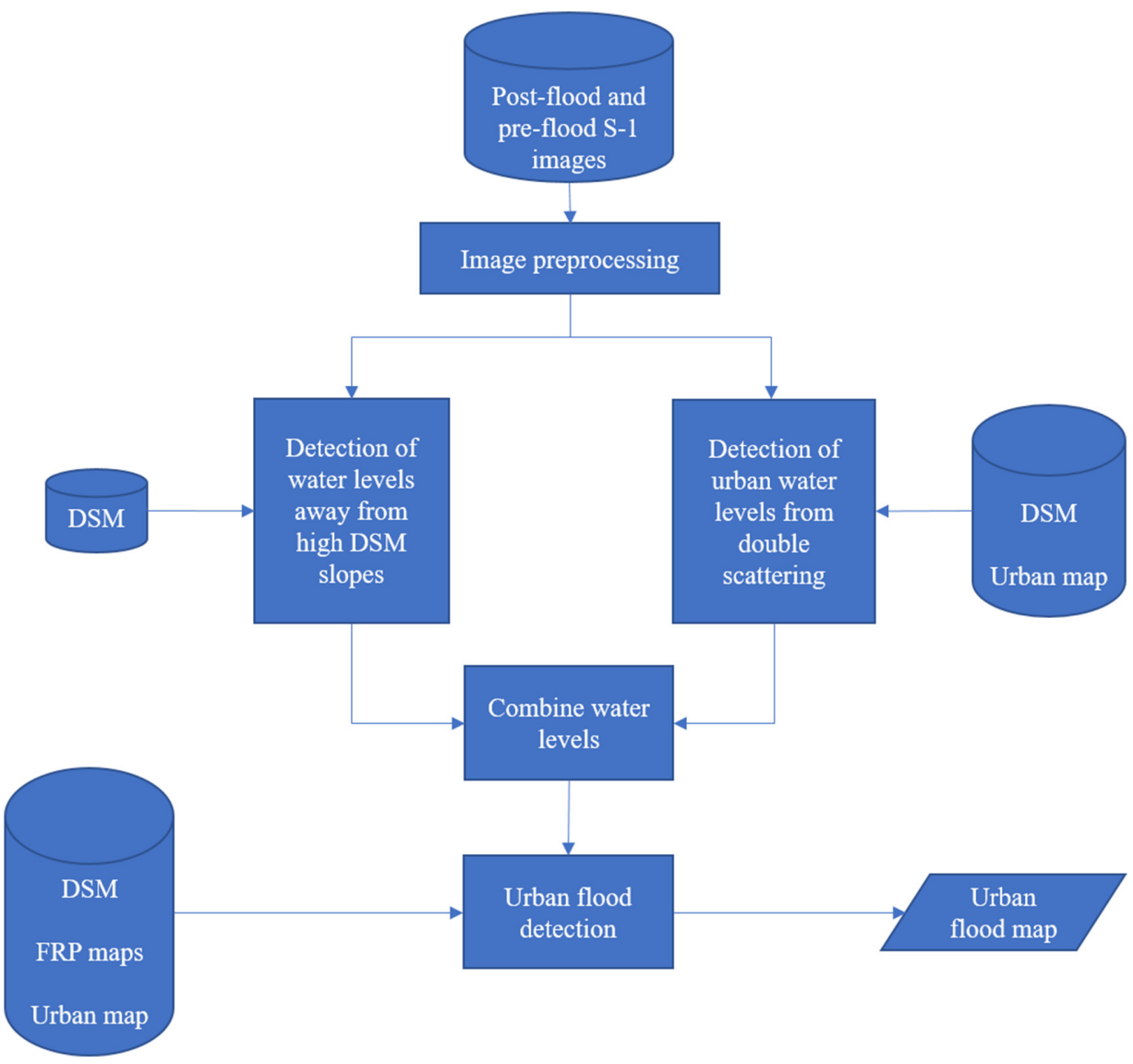

Fig. 5 System flow diagram. 


\section{Method}

The system flow diagram is shown in Fig. 5. The SAR inputs to the method are a postflood S-1 image together with a preflood S-1 image along the same track. Input are also the appropriate areas of the WorldDEM DSM and the World Settlement map. If available, FRP maps of the area may be input to account, for example, for urban regions protected by embankments.

The method searches for two types of WLO, and is comprised of a number of steps a-e. It is illustrated using examples from the Fishlake flood.

a. First, edges of flood regions in the postflood image that are away from high DSM slopes are used to estimate WLOs at the waterline by intersecting the flood regions with the DSM. Such WLOs will mainly be detected in rural areas, but may also occur in urban areas e.g., in parks.

b. Second, in urban areas, water levels are detected using double scattering from buildings that are appropriately oriented with respect to the satellite track.

c. These two types of WLO are combined to form a spatially varying water level threshold surface.

d. If FRP maps are available, they can be used to modify the DSM if necessary to cope with protected urban regions.

e. Those urban pixels with DSM heights below the water level threshold are classed as flooded.

\subsection{Estimation of Water Levels Away from High DSM Slopes}

Flooded areas in the DSM are first mapped using the 'bare soil flood mapping' algorithm developed in Ref. 42. This compares backscatter intensities from an S-1 post-flood image with those from a preflood image. The algorithm has been implemented as the HASARD system on the ESA Grid Processing on Demand platform.

Prior to the application of the algorithm, the HASARD system first performs all the preprocessing steps that need to be applied to each SAR image, using the ESA SNAP toolbox. The preprocessing steps include precise orbit correction, radiometric calibration, thermal noise removal, speckle reduction, terrain correction, and reprojection to the WGS84 coordinate system.

The HASARD flood mapping algorithm is based on adaptive thresholding of the SAR backscatter using a hierarchical approach, such that regions falling below the threshold in the postflood image are classed as flooded, while those above are unflooded. The method exploits multitemporal information to detect changes and contextual information through region growing. Permanent water bodies are suppressed using change detection.

The HASARD system outputs a binary flood extent map, which is subjected to further processing. Waterlines are detected in the map by applying the Sobel edge detector. ${ }^{53}$ To increase accuracy and suppress false alarms, waterline levels in regions that are sufficiently far $(11 \mathrm{~m})$ from high (>0.5) DSM slopes are selected, provided they are within the expected height range of flooding. A waterline level is likely to be determined more accurately on a low slope. This also avoids false alarms near high DSM slopes, which may give rise to shadow/layover areas. These waterlines away from high DSM slopes will largely occur in rural areas, but may also be found in urban areas.

These regions are unlikely to occur on completely bare soils but rather in fields that are vegetated to some extent. The heights of their WLOs may be slightly under estimated due to vegetation height not being taken into account in the bare soil algorithm. Pixels adjacent to low-slope flooded regions may have high rather than low backscatter because of double scattering in vegetation that is flooded but still emergent. To cope with this, these flood regions are modified by merging into them pixels that are adjacent to them and have high scattering ratios between post- and preflood images.

Figure 6 shows the flood extent determined by HASARD for Fishlake on November 14, 2019, together with post- and preflood S-1 subimages after preprocessing. Figure 6 shows flooding in the rural areas surrounding the village, but little flooding in the urban area because backscatter here is higher than the threshold used in HASARD. 


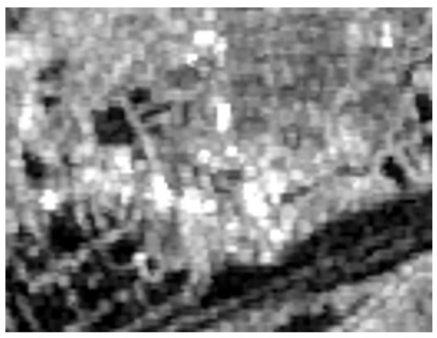

(a)

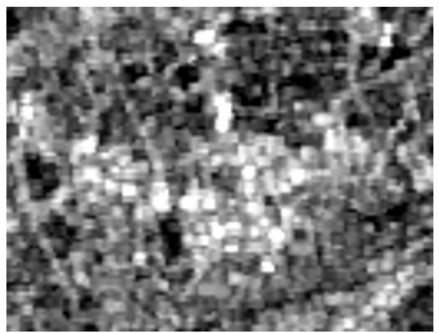

(b)

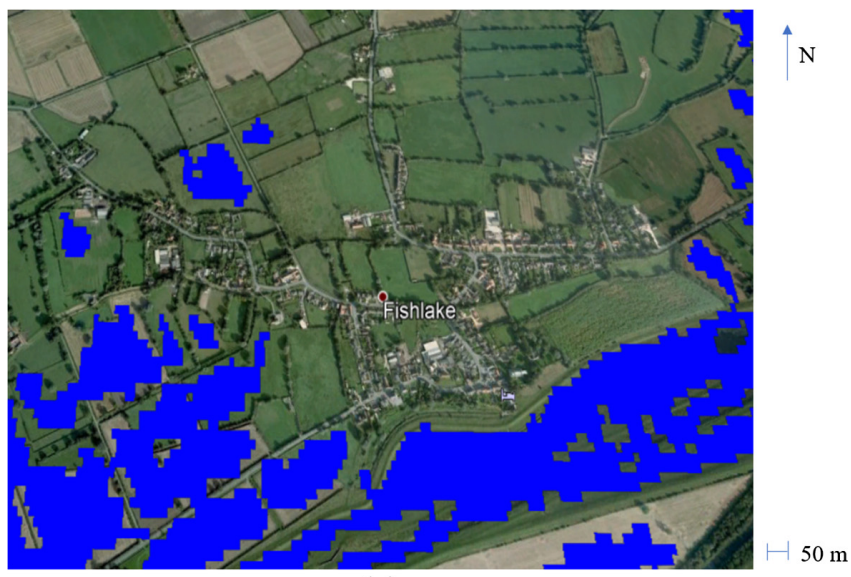

(c)

Fig. 6 (a) Postflood S-1 intensity subimage of Fishlake flood of November 14, 2019; (b) preflood S-1 subimage of Fishlake of September 15, 2019; and (c) "bare-earth" flood map produced by HASARD (flood-water = blue; WGS84 coordinate system).

\subsection{Estimation of Water Levels from Double Scattering in Urban Areas}

In dense urban areas, there would be little flooding identified by HASARD because of the high postflood backscatter that often occurs there due to double scattering between flooded roads and adjacent building walls. This mechanism may be used to identify urban flooding.

Strong edges in the DSM (mainly corresponding to building edges) are first detected using a Roberts edge detector. ${ }^{53}$ This calculates the magnitude and direction of the local gradient at a pixel using a small $2 \times 2$-pixel window centered on the pixel. The Roberts detector is used rather than a more robust one having a larger kernel (e.g., Sobel) because the width of streets in dense urban areas may be comparable to the DSM pixel size. Edges having too large an aspect angle $\varphi$ to the satellite direction of travel ( $>35 \mathrm{deg}$ ) are suppressed, as the SAR image is unlikely to exhibit substantial double scattering at these edges. Because the aspect angle calculated may be rather noisy using the Roberts operator, selected pixels are also required to have not too low a backscatter in the preflood image, on the basis that a correctly oriented double scatterer should give a reasonable backscatter even in the preflood image. A caveat is that such pixels should not have too high an elevation to avoid selecting pixels of high backscatter from sloping roofs.

At each edge pixel, the pixel and the immediate neighbor on either side of it along a line centered on the edge pixel and perpendicular to its edge direction are selected. These three pixels are examined to find the maximum intensity ratio between the postflood and the preflood images, the maximum DSM height (assumed to be from a building roof), and the minimum DSM height. The minimum height is required to be in the height range expected for flooding to reduce outliers from heights above reasonable flood levels. It is assumed that the minimum height is the local ground height where the DSM and the Digital Terrain Model (DTM) coincide, so that there is no need to generate a separate DTM from the DSM prior to the processing. As a check, at this stage, the DTM heights of the edge pixels are regressed against their intensity ratios, as DTM heights should in general fall as intensity ratios rise.

A set of strong edge pixels is chosen that have high intensity ratios and are likely to be mainly flooded, together with another set whose members have ratios close to 1 and are likely mainly unflooded. A condition of set membership is that each member of the first set must be spatially close to a member of the second set, and vice versa. This condition ensures that the flooded double scattering pixels are chosen to be near the flood edge, so that their flood depths are likely to be shallow, as required by Eq. (3). The average DTM heights are estimated for pixels in both sets. The averaging process is essential to reduce the noise in the DTM heights of the individual double scatterers. ${ }^{54}$ It is assumed that double scattering is largely from unvegetated roads and 


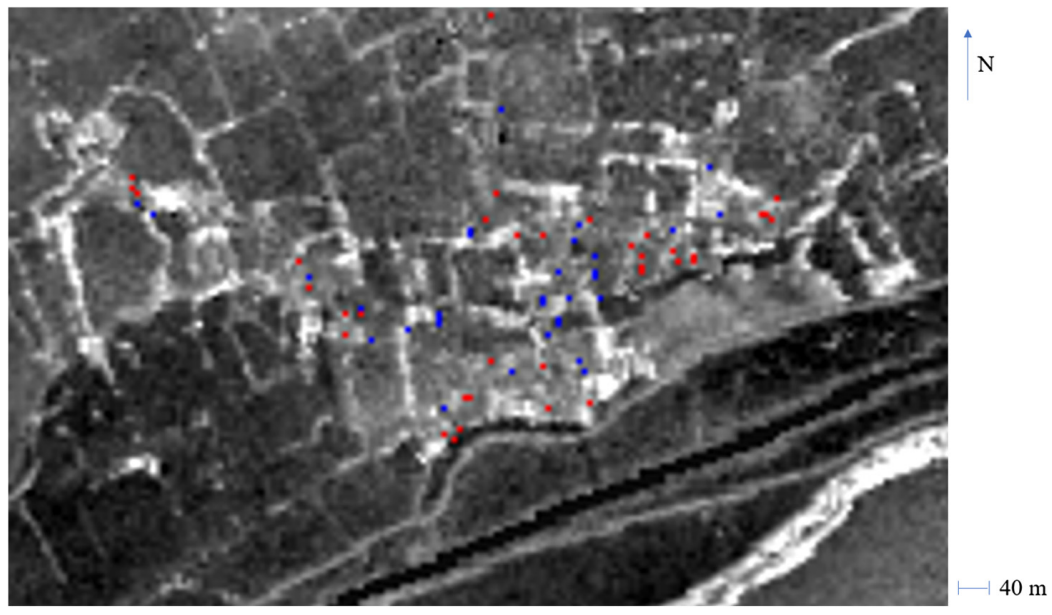

Fig. 7 WorldDEM DSM for Fishlake urban area, with double scattering points for descending-pass S-1 image of November 14, 2019, superimposed (height range $=0$ to $19 \mathrm{~m}$, lighter gray = higher, blue/red = flooded/unflooded double scatterers; BNG coordinate system).

pavement, and that the DTM varies reasonably slowly in the vicinity of the flood edge. To test this latter hypothesis, a t-test is performed on the two averages to check that they are not significantly different. Provided this is so, the local flood height is then chosen as the mean of the flooded and unflooded average DTM heights. The idea in estimating this local flood height is to try to find WLOs at double scattering pixels on both sides of the waterline and close to it in the urban area. This is somewhat analogous to finding WLOs on waterlines in rural areas.

If there are insufficient pixels with intensity ratios close to 1 , this indicates that all of the urban area is flooded. In this case, the method will give no result, and it is assumed that a water level threshold can be constructed from flooding of nearby rural areas. If there are insufficient pixels with large intensity ratios, this indicates that none of the urban area is flooded and the local flood height is set to the DSM height below which only a small percentage of lower heights in the urban area lie.

In regions that are predominantly urban, the number of WLOs that are far from high slopes in the DSM may fall, but the number of WLOs from double scattering should rise to compensate.

Figure 7 shows the accepted double scattering points for flooded and unflooded pixels for the Fishlake urban area for the image of November 14, 2019, superimposed on the WorldDEM DSM. This is a descending pass image and S-1 is right-looking, so that most of the double scattering points should lie immediately to the east of buildings, which does appear to generally be the case.

It should be noted that the polarization of the S-1 images in IW mode is Vertical-Vertical (VV). Considering a double scattering wall-ground combination and assuming a brick wall of complex dielectric constant 4.53 - j0.31 as given in Ref. 41, its Brewster angle is $65 \mathrm{deg}$. If the SAR incidence angle at the ground is $25 \mathrm{deg}$, it will be incident on the wall at the Brewster angle. ${ }^{45}$ At this angle, reflection from the wall will be extinguished, and the wall-ground combination will no longer act as a high-intensity double scatterer, in either the pre- or postflood image. It is, therefore, important that the local incidence angle at the study sites considered is $>25 \mathrm{deg}$. In fact, the S-1 incidence angle range in IW mode is $29.1 \mathrm{deg}$ to $46 \mathrm{deg}$, and in Table 1 it is shown that the local incidence angles are greater than the minimum.

A further point is that the range position of the double reflection from a building in the postflood image is shifted toward the near range compared to its position in the preflood image, ${ }^{41}$ due to the depth of the floodwater $\left(h_{W}-h_{G}\right)$. According to Eq. (9) of Ref. 41, the slant range is reduced by $\left(h_{W}-h_{G}\right) \cos \theta$. However, as it has been assumed that the flooding depth is small near the flood edge, the reduction is small compared to the slant range pixel size after multilooking.

Coherence between pre- and postflood images has been shown to be a useful adjunct for detecting flooding in urban areas, though SAR intensity still appears to be the dominant measure. ${ }^{4,37-39}$ Compared to using double scattering, coherence may not be so useful in high density urban housing because of the averaging operation over a large window required to measure it and the consequent reduction in spatial resolution, especially using S-1 images. 
However, it might still be useful in urban areas where the buildings are not oriented to produce much double scattering. While coherence has not been used here, the method could easily be modified to accept coherence as an additional measure of urban flooding.

\subsection{Combining Water Levels}

At this stage, the WLOs from pixels away from high slopes in the DSM are combined with the WLOs estimated by double scattering in urban areas.

To take into account the fall-off of water level down the reach and that different parts of a domain may be flooded to different depths, a local combination method is used in which the domain is subdivided into nonoverlapping rectangular $m \times n$-pixel subdomains of $\sim 1$-km side. Within each subdomain, an average water level is calculated from WLOs of pixels away from high slopes, together with a further average of WLOs from double scattering. The combined water level for the subdomain is calculated as the weighted mean of these two averages, with the weighting being determined by the number of WLOs of each type. If there are only WLOs of one type available in a subdomain, the average water level for that type is taken as the average for the subdomain. If there are no WLOs of either type available for a subdomain, its water level is set to that of the nearest subdomain with a high proportion of urban coverage. A water level surface $\mathrm{O}(x, y)$ for the whole domain is then obtained by performing linear interpolation between the water levels of the individual subdomains.

\subsection{Modification of the DSM by Flood Return Period Maps}

If FRP maps are available, they can be used to modify the DSM, if necessary, in a preprocessing operation. ${ }^{36}$ The advantage of FRP maps is that if there are urban areas that are lower than the flooding but protected from it (e.g., by embankments), this information should be contained in the maps, which would assign high return periods to such areas.

Details of the method are given in Ref. 36. The first stage is to estimate the return period $r p(x, y)$ of each point in the floodplain using the FRP maps provided by public bodies. Usually, 3 to 5 maps are made available, and for each pair of contiguous maps, an interpolation technique is applied to derive intermediate FRP maps. Regions classed as flooded due to low backscatter in the postflood SAR image are used to estimate a return period for the flood. Floodplain pixels having return periods $r p(x, y)$ less than this estimate are classed as flooded. If some portion of the urban area is protected, this will be encapsulated in the FRP maps as high return periods at the protected pixels, which will result in these not being classed as flooded. It is worth noting that a disadvantage of the FRP maps is they do not contain information about any temporary barriers erected to mitigate the flooding.

A further difficulty with FRP maps is that it may be difficult to access them rapidly in an emergency. However, it would still be possible to obtain an urban flood detection accuracy without the FRP data, though it may be an overestimate of the urban flooding because protected urban areas are not screened out from the flooding.

\subsection{Flood Detection in Urban Areas}

The final stage is to extract urban water regions from the effective height image $e f f \_h(x, y)$ using the water level surface $O(x, y)$. For pixels in urban areas

$$
\text { if } e f f \_h(x, y)<O(x, y, t) \text {, pixel is flooded, else not flooded, }
$$

where $e f f \_h(x, y)$ is the DSM height (possibly modified) at $(x, y)$.

\section{Results}

\subsection{Fishlake}

Table 1 gives details of the two postflood images analyzed for Fishlake on November 11, 2019, and November 14, 2019, together with their associated preflood images. 
Both these image pairs were processed by the HASARD system, with the small object size limit set to 10 pixels (Sec. 4.1). The flood extent map produced by HASARD for November 14, 2019, shows flooding in the rural area surrounding Fishlake, but little flooding in the urban area itself because of double scattering raising the SAR backscatter here (Fig. 6). The flood extent map for November 11, 2019, was very similar to Fig. 6.

The SNAP toolbox was used to collocate the WorldDEM DSM and SAR intensity maps, and to reproject these from WGS84 to the British National Grid (BNG) coordinate system, for comparison with the EA LiDAR data at the validation stage.

In the double scattering analysis (Sec. 4.2), edges in the DSM were required to be at least $2-\mathrm{m}$ high. Correctly oriented edge pixels were defined as having high intensity ratios $\left(\sigma^{0}{ }_{w} / \sigma^{0}{ }_{g}\right)$ if their ratios were $>2.5$, and having ratios close to 1 if these were $<2$. An edge pixel having high (low) intensity ratio was required to be within $150 \mathrm{~m}$ of a pixel of low (high) intensity ratio to be included in the set of high (low) ratio edges. For both postflood image dates, the slopes of the regression line of the DTM heights of the double-scattering edge pixels against their intensity ratios were slightly negative, in keeping with the expectation that DTM heights should fall as intensity ratios rise.

At the stage of combining water levels from both types of WLO (Sec. 4.3), the $3 \times 3 \mathrm{~km}^{2}$ domain of the Fishlake area [Fig. 8(a)] was subdivided into nonoverlapping square subdomains of $1-\mathrm{km}$ sides.

From the EA flood risk map, ${ }^{55}$ the area flooded has a low risk of flooding, with an AEP of between $0.1 \%$ and $1 \%$, as the river Don is constrained within high flood barriers as it flows past Fishlake. Because there were no sharp discontinuities in risk in the urban area, there was no need to use the flood risk map to modify the DSM to account for high return periods in protected areas (Sec. 4.4).

The aerial photos were used in conjunction with the 2-m EA LiDAR data to construct validation flood images. It was found by manual inspection that a simple flood-fill of the LiDAR DSM up to the level of the waterline in the aerial photos could match the flooding in the aerial photos for each postflood S-1 image date. This was a straightforward way of extracting the waterline from the aerial photos without having to resort to manual digitization. The validation image for each postflood S-1 image date was constructed at the WorldDEM DSM resolution by applying the relevant flood-fill height threshold in the WorldDEM DSM. There appeared to be

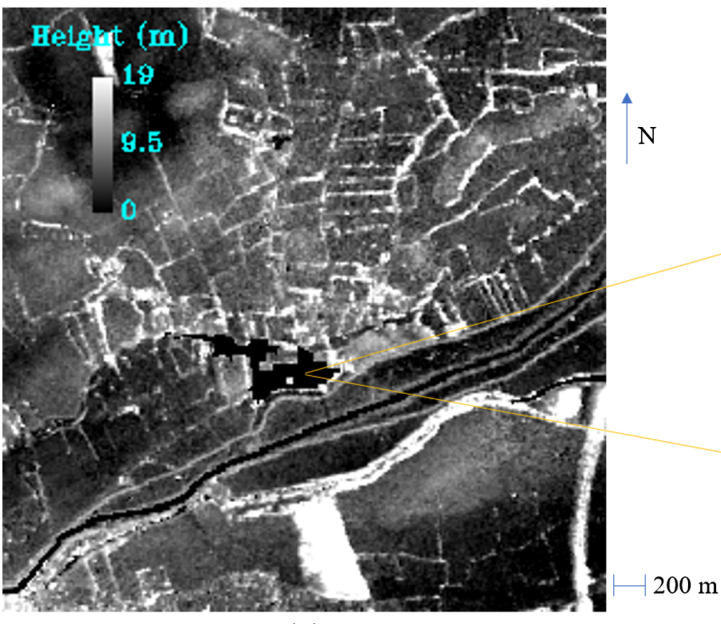

(a)

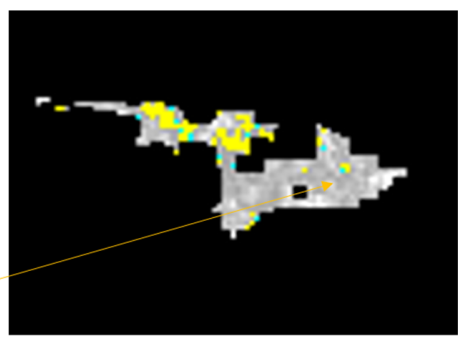

(b)

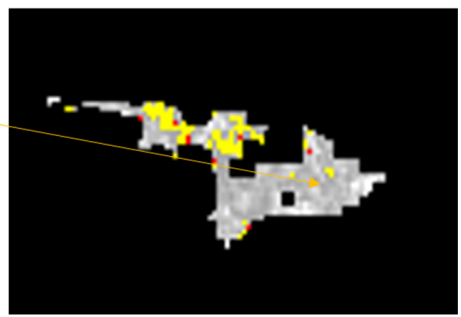

(c)

Fig. 8 (a) WorldDEM DSM of Fishlake area $\left[3 \times 3 \mathrm{~km}^{3}\right.$, urban area visible in aerial photos masked out (black)]; (b) correspondence between SAR image of November 11, 2019, and aerial photo flood extent in urban area that is visible in aerial photos, superimposed on the WorldDEM image (lighter gray = higher; yellow, wet in SAR and aerial photos; red, wet in SAR only; and cyan, wet in aerial photos only); and (c) as (b) but for SAR image of November 14, 2019. 
Table 2 Flood heights of both WLO types and validation images, for central $1 \times 1 \mathrm{~km}^{2}$ subdomain of Fig. 8(a). Errors quoted are standard errors on the means.

\begin{tabular}{lcccccc}
\hline \hline & $\begin{array}{c}\text { Mean height of } \\
\text { water levels } \\
\text { away from high } \\
\text { slopes }(\mathrm{m}) /\end{array}$ & $\begin{array}{c}\text { Mean height of } \\
\text { flooded double } \\
\text { scatterers } \\
(\mathrm{m}) /(\text { no. of } \\
\text { samples) }\end{array}$ & $\begin{array}{c}\text { Mean height } \\
\text { of unflooded } \\
\text { double } \\
\text { scatterers } \\
(\mathrm{m}) /(\mathrm{no} \text {. of } \\
\text { samples) }\end{array}$ & $\begin{array}{c}\text { Mean of flooded } \\
\text { and unflooded } \\
\text { average double } \\
\text { scatterer } \\
\text { heights }(\mathrm{m})\end{array}$ & $\begin{array}{c}\text { Weighted } \\
\text { mean } \\
\text { height of } \\
\text { both WLO } \\
\text { images }(\mathrm{m})\end{array}$ & $\begin{array}{c}\text { Flood height } \\
\text { in Validation } \\
\text { image }(\mathrm{m})\end{array}$ \\
\hline $\begin{array}{l}\text { November } \\
11,2019\end{array}$ & $\begin{array}{c}3.71 \pm 0.03 \\
(174)\end{array}$ & $\begin{array}{c}4.06 \pm 0.08 \\
(21)\end{array}$ & $\begin{array}{c}4.10 \pm 0.07 \\
(38)\end{array}$ & $4.08 \pm 0.04$ & $3.83 \pm 0.03$ & 3.95 \\
$\begin{array}{l}\text { November } \\
14,2019\end{array}$ & $\begin{array}{c}3.78 \pm 0.09 \\
(33)\end{array}$ & $\begin{array}{c}3.96 \pm 0.10 \\
(32)\end{array}$ & $\begin{array}{c}3.95 \pm 0.11 \\
(33)\end{array}$ & $3.95 \pm 0.05$ & $3.91 \pm 0.05$ & 3.85 \\
\hline \hline
\end{tabular}

little bias between the WorldDEM and LiDAR DSMs over this area. The mean flood height was slightly lower in the image of November 14, 2019, than that of November 11, 2019, as the flood was slowly receding during this period.

The urban area of Fishlake turned out to have a mixture of WLOs from nearby rural areas and WLOs from urban double scatterers. Table 2 gives the mean flood heights of the two types of WLO, together with those of the validation images, for the central $1 \times 1 \mathrm{~km}^{2}$ subdomain of the Fishlake area containing the village. It can be seen that, for both flood image dates, the mean height of water levels away from high DSM slopes is lower than the mean of the flooded and unflooded double scatterer average heights, in the case of November 11, 2019, significantly so. A possible reason for this is that the water levels of WLOs away from high slopes were being underestimated due to the vegetation height corrections to the HASARD bare soil algorithm being too small. The correction was only a few $\mathrm{cm}$, whereas it might be expected to be 10 to $20 \mathrm{~cm}$ or so.

Figure 8(b) shows the class correspondence between the S-1 image of November 11, 2019, and the aerial photo flood extent in the urban area that was visible in the aerial photography, superimposed on the WorldDEM image. Figure 8(c) shows the correspondence for the S-1 image of November 14, 2019.

The performance measures used to assess the flood detection accuracy were the flood detection rate [i.e., Recall $\left.=t_{p} /\left(t_{p}+f_{n}\right)\right]$, the Precision $\left[=t_{p} /\left(t_{p}+f_{p}\right)\right]$, and the critical success index [CSI $\left.=t_{p} /\left(t_{p}+f_{p}+f_{n}\right)\right]$, where $t_{p}=$ true positives, $f_{n}=$ false negatives, and $f_{p}=$ false positives.

Table 3 gives the performance measures in the urban area for November 11, 2019, and November 14, 2019. For both dates, there was a good flood detection rate $(87 \%$ and $100 \%$, respectively), with associated high rates of Precision and CSI.

The relationship between the intensity ratio and the angle $\varphi$ between the wall of the double scatterer and the SAR direction of travel was also examined. The object was to measure how fast the ratio fell as $\varphi$ increased from $0 \mathrm{deg}$. If the fall was very rapid, this might reduce the number of double scatterers that could be distinguished as flooded or unflooded in the postflood image. A set of 10 reasonably isolated unambiguous flooded double scatterers was identified in the Fishlake image of November 14, 2019. These had building heights in the range 4 to $6 \mathrm{~m}$ and flood heights $<1 \mathrm{~m}$. For each building, the angle $\varphi$ and building height were measured manually in the 2-m LiDAR DSM. This approach was taken because these variables measured using the WorldDEM DSM were rather inaccurate. Figure 9 shows the relationship between the ratio and

Table 3 Urban flood detection accuracy.

\begin{tabular}{lccc}
\hline \hline Postflood image & $\begin{array}{c}\text { Flood detection } \\
\text { rate (recall) (\%) }\end{array}$ & Precision (\%) & CSI (\%) \\
\hline November 11, 2019 & 87 & 100 & 87 \\
November 14, 2019 & 100 & 92 & 92 \\
\hline \hline
\end{tabular}




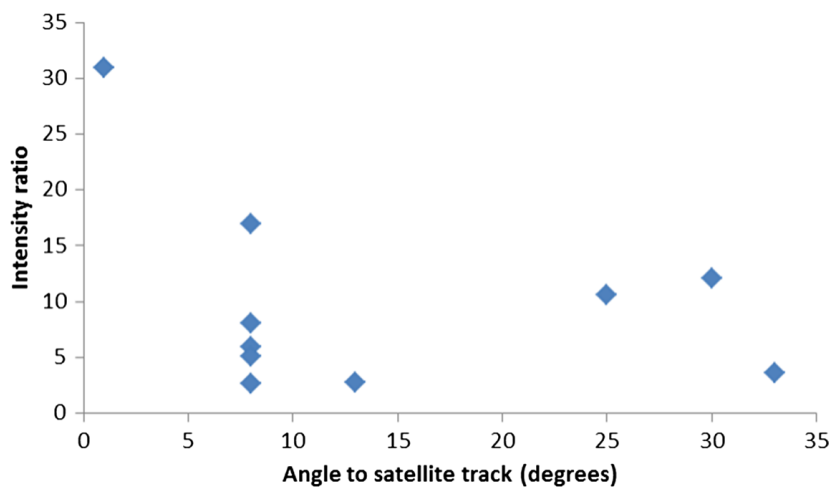

Fig. 9 Relationship between S-1 intensity ratio and angle $\varphi$ to satellite track.

$\varphi$. Although the sample size is small, the data are not inconsistent with a peak at $\varphi=0$ deg with a rapid fall off as predicted by Ref. 37, though there are still a significant number of ratios $>2.5$ at angles $>10$ deg.

\subsection{Pontypridd}

The postflood image of February 16, 2020, and its preflood associate (Table 1) were processed by the HASARD system, with the small object size limit set to 10 pixels. Figure 10 shows the flood extent map produced by HASARD, together with post- and preflood S-1 subimages after preprocessing. HASARD detected flooding in the rural part of the valley north of Pontypridd, but little flooding in the urban area itself because of double scattering raising the SAR backscatter here.

The urban area of Pontypridd proved to be a stiff test of the method because of its narrow streets of terraced houses with high housing density, set in a valley with steep-sloping sides (Fig. 11). Figure 11(b) shows an extract from the WorldDEM DSM covering the center of Pontypridd, and Fig. 11(c) shows the LiDAR DSM averaged to the same 12-m scale. While it is to be expected that many streets will be missing in the WorldDEM DSM because their widths are less than the WorldDEM resolution, it is also apparent that there is more sensible structure and less noise in the downscaled LiDAR.

In the double scattering analysis, the same edge strength, intensity ratio, and distance thresholds were used as in the Fishlake case. Figure 12 shows the accepted double scattering points for

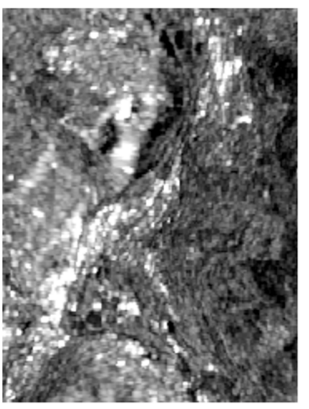

(a)

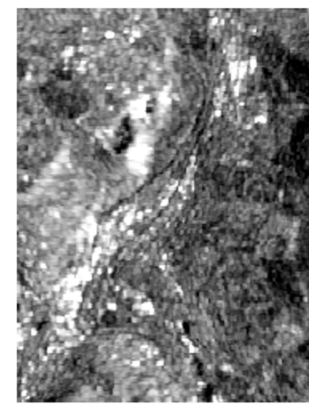

(b)

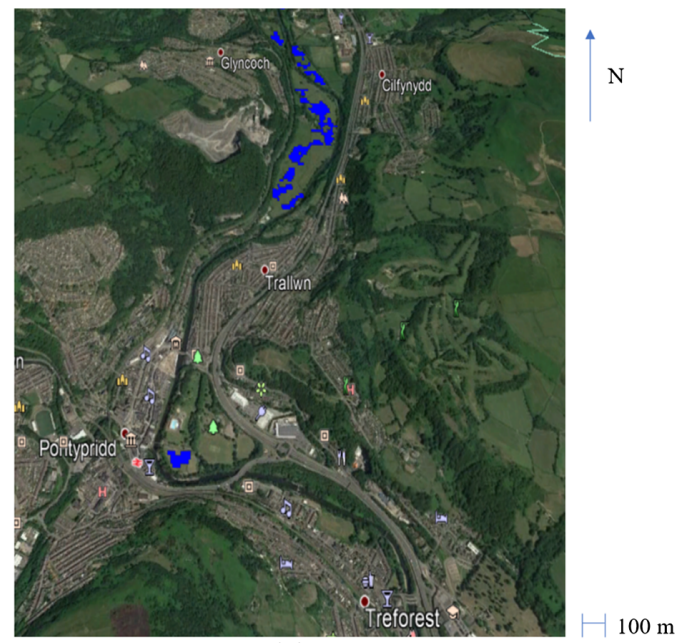

(c)

Fig. 10 (a) Postflood S-1 intensity subimage of Pontypridd flood of February 16, 2020; (b) preflood S-1 subimage of Pontypridd of February 14, 2020; and (c) "bare-earth" flood map produced by HASARD (flood-water = blue; WGS84 coordinate system). 


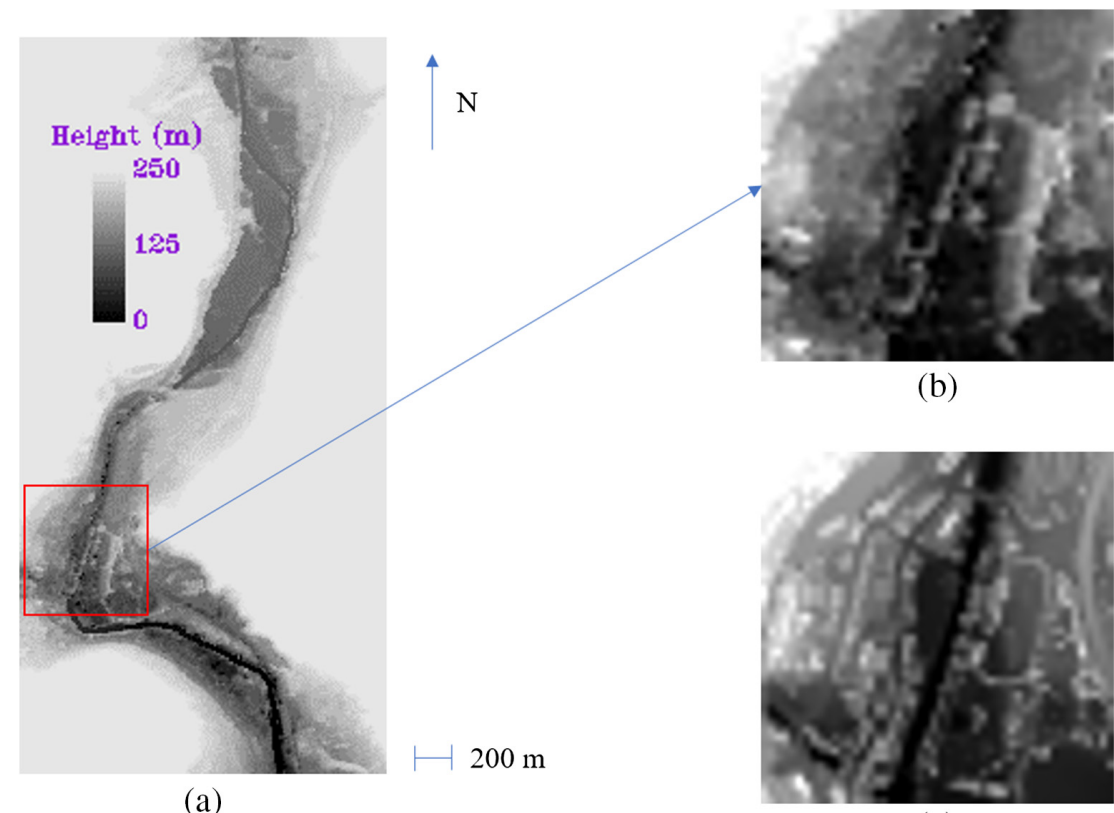

(c)

Fig. 11 (a) WorldDEM DSM of Pontypridd area; (b) expanded view of WorldDEM DSM in red rectangle covering town center; and (c) downscaled LiDAR DSM of red rectangle (BNG coordinate system).

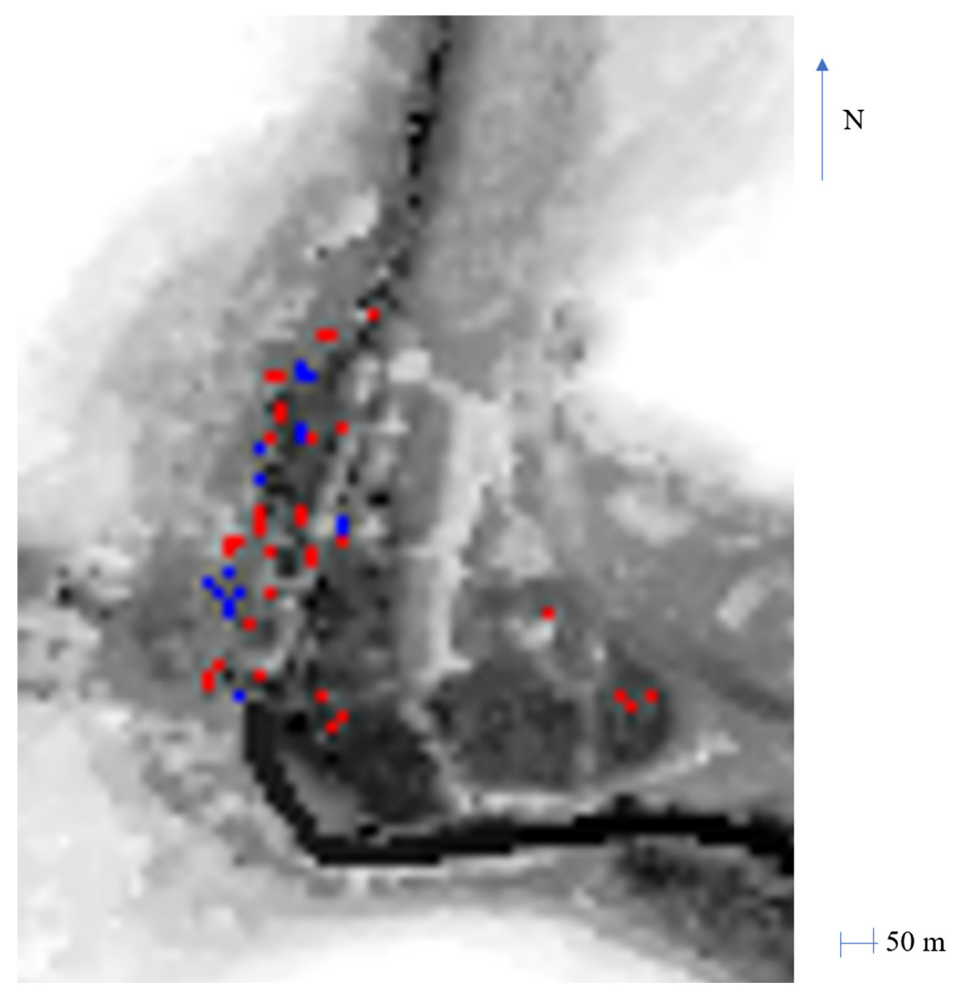

Fig. 12 WorldDEM DSM for Pontypridd urban area with double scattering points for descendingpass S-1 image of February 16, 2020, superimposed (height range $=46$ to $138 \mathrm{~m}$, lighter gray = higher, blue/red = flooded/unflooded double scatterers). 


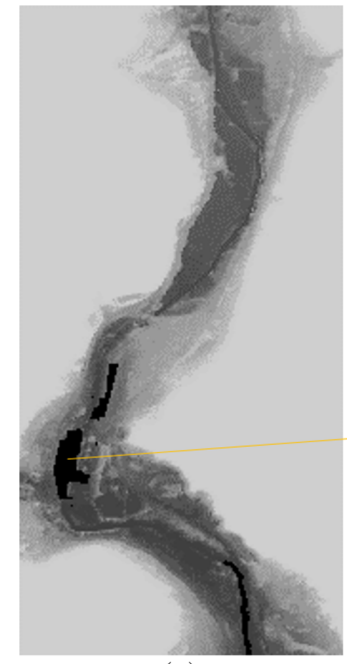

(a)

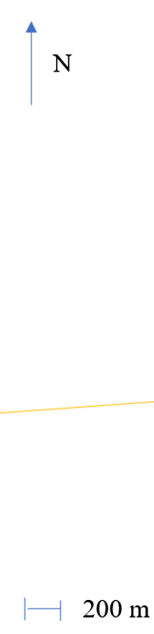

Fig. 13 (a) WorldDEM DSM of Pontypridd area $\left(2 \times 4 \mathrm{~km}^{2}\right.$, urban area visible in aerial photos masked out); (b) correspondence between SAR image of February 16, 2020, and aerial photo flood extent in urban area that is visible in aerial photos, superimposed on the WorldDEM image (lighter gray = higher; yellow, wet in SAR and aerial photos; red, wet in SAR only; and cyan, wet in aerial photos only).

flooded and unflooded pixels for the Pontypridd urban area for the image of February 16, 2020, superimposed on the WorldDEM DSM. The S-limage was again descending pass and rightlooking, so that most of the double scattering points should lie immediately to the east of buildings, which often does appear to be the case. Both the flooded and the unflooded double scatterers seem to be located in sensible places.

The domain used for the Pontypridd flood was $2 \times 4 \mathrm{~km}^{2}$, as the urban areas are largely confined to the lower areas near the valley bottom [Fig. 13(a)]. For the purpose of combining the two WLO types, the domain was subdivided into four nonoverlapping rectangular subdomains of size $2 \times 1 \mathrm{~km}^{2}$ each. The section of Pontypridd subject to flooding lay in rectangle $(0,2)$ [with $(0,0)$ being furthest north]. This subdomain had no WLOs from areas away from high DSM slopes, and the WLOs measured were all due to double scattering from buildings.

From the Natural Resources Wales flood risk map, ${ }^{56}$ the area flooded has a low risk of flooding, with an AEP of between $0.1 \%$ and $1 \%$. Because the whole of the urban area had the same $\mathrm{AEP}$, there was no need to use the flood risk maps to modify the DSM to account for high return periods in protected areas.

The aerial photos were used to construct a validation flood image at the WorldDEM DSM resolution by the method used for Fishlake. The river was not included in the flood class.

Table 4 gives the mean flood height of the double scatterers, together with that of the validation image, for the rectangular $2 \times 1 \mathrm{~km}^{2}$ urban subdomain of the Pontypridd area at $(0,2)$. There were no WLOs from pixels away from high slopes in this subdomain, so that the mean flood height was estimated solely from double scattering. Unlike the Fishlake case, the slope of

Table 4 Flood heights of both WLO types and validation images, for $2 \times 1 \mathrm{~km}^{2}$ subdomain covering central Pontypridd. Errors quoted are standard errors on the means.

\begin{tabular}{|c|c|c|c|c|c|c|}
\hline $\begin{array}{l}\text { Postflood } \\
\text { image }\end{array}$ & $\begin{array}{l}\text { Mean height } \\
\text { of water levels } \\
\text { away from } \\
\text { high slopes } \\
\text { (m)/(no. of } \\
\text { samples) }\end{array}$ & $\begin{array}{l}\text { Mean height of } \\
\text { flooded double } \\
\text { scatterers (m)/ } \\
\text { (no. of samples) }\end{array}$ & $\begin{array}{l}\text { Mean height } \\
\text { of unflooded } \\
\text { double } \\
\text { scatterers } \\
\text { (m)/(no. of } \\
\text { samples) }\end{array}$ & $\begin{array}{l}\text { Mean of flooded } \\
\text { and unflooded } \\
\text { average double } \\
\text { scatterer } \\
\text { heights }(\mathrm{m})\end{array}$ & $\begin{array}{l}\text { Weighted } \\
\text { mean height } \\
\text { of both WLO } \\
\text { types }(\mathrm{m})\end{array}$ & $\begin{array}{c}\text { Flood height } \\
\text { in Validation } \\
\text { image }(\mathrm{m})\end{array}$ \\
\hline $\begin{array}{l}\text { February } \\
16,2020\end{array}$ & $\begin{array}{c}\text { No level } \\
\text { calculated (0) }\end{array}$ & $\begin{array}{c}55.72 \pm 0.43 \\
(16)\end{array}$ & $\begin{array}{c}55.51 \pm 0.31 \\
(27)\end{array}$ & $55.61 \pm 0.18$ & $55.61 \pm 0.18$ & 55.90 \\
\hline
\end{tabular}


Table 5 Urban flood detection accuracy.

\begin{tabular}{lccc}
\hline \hline Postflood image & $\begin{array}{l}\text { Flood detection } \\
\text { rate (recall) }(\%)\end{array}$ & Precision (\%) & CSI (\%) \\
\hline February 16, 2020 & 72 & 63 & 51 \\
$\begin{array}{l}\text { February 16, 2020 } \\
\text { (deblurred DSM) }\end{array}$ & 64 & 51 & 40 \\
\hline \hline
\end{tabular}

the regression line of the DTM heights of the double-scattering edge pixels against their intensity ratios was slightly positive, so that the mean height of the flooded double scatterers was slightly higher than that of the unflooded ones. This may be due to limitations in the DSM in this scenario. Even so, the overall weighted mean height was not significantly lower than the flood height estimated from the validation image.

Figure 13(b) shows the class correspondence between the S-1 image of February 16, 2020, and the aerial photo flood extent in the urban area that was visible in the aerial photography, superimposed on the WorldDEM image. Table 5 gives the flood detection performance measures in the urban area for February 16, 2020. At $72 \%$ accuracy, the flood detection rate can only be described as reasonable, while the Precision is reduced (63\%) because there are a substantial number of false positives. These inaccuracies are partly caused by the fact that the streets in Pontypridd are so narrow that the WorldDEM DSM may overestimate the height in the streets, so that they are not classed as flooded. For example, the flooding in Taff Street has not been detected [cyan in Fig. 13(b)], though that in Sion Street has [yellow in Fig. 13(b)]. The high false-positive rate is partly due to an area of the WorldDEM DSM west of the town center being slightly low compared to the LiDAR.

A further difficulty with narrow streets roughly parallel to the satellite track is that the backscatter from a double scatterer wall-ground combination in one street may be affected by that from the roof of a house in the next street farther in ground range from the satellite. In this case, the return from the roof may fall into the same slant range bin as that from the double scatterer. The return from the roof is likely to be strong, though as the roof would be unflooded in the postflood image, its intensity ratio may be 1 . If the double scatterer happens to be flooded, the additional signal from the roof may reduce the intensity ratio for the double scatterer.

It is clear from the above results that a DSM with higher spatial resolution than that of WorldDEM would be beneficial for detecting urban flooding for the Pontypridd flood. A higher resolution version of WorldDEM (HDEM) has been developed using the TanDEM-X mission data. ${ }^{57} \mathrm{HDEM}$ relies on several new acquisitions with larger baselines resulting in smaller height errors from phase noise, giving a DSM with 6-m pixel size yet similar height accuracy to WorldDEM. However, only selected areas of the globe have been processed, so that HDEM is not a publicly available global DSM. Nonlocal Interferometric SAR (InSAR) filters have also been used to generate higher resolution DSMs from TanDEM-X data, though again these are not publicly available and global. ${ }^{58}$ An airborne InSAR 5-m DSM is available for Pontypridd instead of WorldDEM under the NEXTMap Britain program. ${ }^{59}$ Airborne InSAR data at 5-m resolution are available at both national and regional scales, but are mainly confined to Western Europe, North America, and the Middle East, and again are not global.

We also investigated whether image deblurring could be used to improve the WorldDEM DSM prior to detecting urban flooding using it. Blind deconvolution was applied to an upscaled version of the DSM having half the pixel spacing $(6 \mathrm{~m})$ of the original. The iterative deconvolution method in MATLAB ${ }^{\circledR}$ was used, which restored the image and the point spread function (PSF) simultaneously using the Richardson-Lucy algorithm. ${ }^{60}$ Prior to deblurring, the onedimensional (1D) PSF of the WorldDEM image was estimated at a number of sharp edges in the LiDAR DSM. As a result, the initial estimate of the 2D PSF input to the deblurring was normally distributed with a standard deviation of $9 \mathrm{~m}$. The revised PSF after deblurring was very similar to this. The deblurred DSM visually appeared to have more structure in it than the original. Using the deblurred DSM to predict urban flooding produced flooding in Taff Street, but also introduced false positives elsewhere. The urban flood detection rate fell slightly from 
$71 \%$ to $64 \%$, while the Precision fell from $63 \%$ to $51 \%$ because the false-positive rate rose (Table 5). Overall, deblurring of the DSM gave a worse result than the original.

\section{Conclusion}

Remote sensing using SAR is an important tool for emergency flood incident management. At present, operational services are mainly aimed at flood mapping in rural areas, as mapping in urban areas is hampered by the complicated backscattering mechanisms occurring there. A method for detecting flooding at high resolution in urban areas that may or may not contain dense housing has been presented. This is a change detection method that requires only one postflood and one preflood image on the same satellite track. Flood levels in urban areas are estimated locally using increased SAR backscatter in the postflood image due to double scattering between water (rather than unflooded ground) and adjacent buildings, and reduced SAR backscatter in areas away from high DSM slopes. Areas of urban flooding are detected by comparing an interpolated flood level surface to the DSM.

High urban flood detection accuracies with low false-positive rates were obtained for the flood event in Fishlake, where housing density is moderate. The accuracy reduced though was still reasonable for the event in Pontypridd, where housing is dense. In this case, the double scattering method estimated the local flood height correctly in the urban area, but the WorldDEM DSM was not always able to provide sensible ground heights because street widths became comparable to the DSM resolution. A higher resolution DSM is required for this site. The method should also work with airborne InSAR (e.g., NextMap) data instead of the WorldDEM DSM, though for 5-m resolution data, these would be regional rather than global. The results presented demonstrate that the method has promise and can be used to improve flood incident management.

The main data sets used by the method (S-1 images, the WorldDEM DSM and WSF data) are readily available on a global basis. This may not always be the case for FRP maps. However, in both the cases studied the FRP maps were available online, and it was clear by simple inspection that there was no need to use the FRP maps to modify the DSM for either site, because each flooded area had a single AEP over its entirety.

As explained above, UK flood events were studied in this case for ease of validation, but the method should work on a global basis. Future work will be aimed at testing the method on larger urban floods in developing countries. These are less likely to have access to high-resolution DSMs that could act as alternatives to WorldDEM data. More importantly, the risk to life from urban flooding increases as societies become poorer. ${ }^{1}$

\section{Acknowledgments}

This work was funded in part under the UK Engineering and Physical Sciences Research Council Grant No. EP/P002331/1 "Data Assimilation for the Resilient City (DARE)." The data/maps in this report derive partly from material provided through use of the Luxembourg Institute of Science and Technology (LIST) HASARD software (patent pending).

Disclosures: The authors have no competing interests to declare.

\section{References}

1. H. Ritchie, "Natural disasters," 2014, https://ourworldindata.org/natural-disasters.

2. R. E. Munich, "Loss events worldwide 1980-2014, 10 costliest floods ordered by overall losses," 2015, www.munichre.com/natcatservice.

3. H. C. Winsemius et al., "Global drivers of future river flood risk," Nat. Clim. Change 6, 381385. (2015).

4. Y. Li et al., "Urban flood mapping using SAR intensity and interferometric coherence via Bayesian network fusion," Remote Sens. 11, 2231-2252. (2019).

5. M. Pitt, "Learning lessons from the 2007 floods," U.K. Cabinet Office Report, 2008, http:// archive.cabinetoffice.gov.uk/pittreview/thepittreview.html. 
6. S. Grimaldi et al., "Sensing-derived water extent and level to constrain hydraulic flood forecasting models: opportunities and challenges," Surv. Geophys. 37, 977-1034 (2016).

7. J. Garcia-Pintado et al., "Scheduling satellite-based SAR acquisition for sequential assimilation of water level observations into flood modeling," J. Hydrol. 495, 252-266 (2013).

8. J. Garcia-Pintado et al., "Satellite-supported flood forecast in river networks: a real case study," J. Hydrol. 523, 706-724 (2015).

9. D. C. Mason et al., "Automatic near real-time selection of flood water levels from high resolution synthetic aperture radar images for assimilation into hydraulic models: a case study," Remote Sens. Environ. 124, 705-716 (2012).

10. L. Giustarini et al., "Probabilistic flood mapping using Synthetic Aperture Radar data," IEEE Trans. GeoSci. Remote Sens. 54(12), 6958-6969 (2016).

11. R. Hostache et al., "Near-real-time assimilation of SAR-derived flood maps for improving flood forecasts," Water Resour. Res. 54(8), 5535-5516 (2017).

12. E. S. Cooper et al., "Observation operators for assimilation of satellite observations in fluvial inundation forecasting," Hydrol. Earth Syst. Sci. 23, 2541-2559 (2019).

13. E. S. Cooper et al., "Observation impact, domain length and parameter estimation in data assimilation for flood forecasting," Environ. Modell. Software 104, 199-214 (2018).

14. S. Martinis, A. Twele, and S. Voigt, "Towards operational near real-time flood detection using a split-based automatic thresholding procedure on high resolution TerraSAR-X data," Nat. Hazards Earth Syst. Sci. 9, 303-314 (2009).

15. S. Martinis, A. Twele, and S. Voigt, "Unsupervised extraction of flood-induced backscatter changes in SAR data using Markov image modeling on irregular graphs," IEEE. Trans. Geosci. Remote Sens. 49(1), 251-263 (2011).

16. S. Martinis, J. Kersten, and A. Twele, "A fully automated TerraSAR-X based flood service," ISPRS J. Photogramm. Remote Sens. 104, 203-212 (2015).

17. L. Pulvirenti et al., "Flood monitoring using multi-temporal COSMO-SkyMed data: image segmentation and signature interpretation," Remote Sens. Environ. 115(4), 990-1002 (2011).

18. L. Pulvirenti et al., "An algorithm for operational flood mapping from Synthetic Aperture Radar (SAR) data using fuzzy logic," Nat. Hazard Earth Syst. Sci. 11, 529-540 (2011).

19. A. Twele et al., "Sentinel-1 based flood mapping: a fully-automated processing chain," Int. J. Remote Sens. 37(13), 2990-3004 (2016).

20. A. D'Addabbo et al., "Bayesian network for flood detection combining SAR imagery and ancillary data," IEEE Trans. GeoSci. Remote Sens. 54(6), 3612-3625 (2016).

21. A. D'Addabbo et al., "DAFNE: a Matlab toolbox for Bayesian multi-source remote sensing and ancillary data fusion, with application to flood mapping," Comput. Geosci. 112, 64-75 (2018).

22. P. Matgen et al., "Towards an automated SAR based flood monitoring system: lessons learned from two case studies," Phys. Chem. Earth 36, 241-252. (2011).

23. L. Giustarini et al., "A change detection approach to flood mapping in urban areas using TerraSAR-X," IEEE. Trans. Geosci. Remote Sens. 51(4), 2417-2430 (2013).

24. N. Pierdicca et al., "Observing floods from space: experience gained from COSMOSkyMed observations," Acta Astronaut. 84, 122-133 (2013).

25. G. Schumann, G. D. di Baldassarre, and P. D. Bates, "The utility of spaceborne radar to render flood inundation maps based on multialgorithm ensembles," IEEE Trans. Geosci. Remote Sens. 47, 2801-2807 (2009).

26. S. Schlaffer et al., "Probabilistic mapping of flood-induced backscatter changes in SAR time series," Int. J. Appl. Earth Obs. Geoinf. 56, 77-87 (2017).

27. R. S. Westerhoff et al., "Automated global water mapping based on wide-swath orbital synthetic-aperture radar," Hydrol. Earth Syst. Sci. 17, 651-663 (2013).

28. A. Benoudjit and R. Guida, "Novel fully automated mapping of the flood extent on SAR images using a supervised classifier," Remote Sens. 11, 779 (2019).

29. E. Nemni et al., "Fully convolutional neural network for rapid flood segmentation in synthetic aperture radar imagery," Remote Sens. 12, 2532 (2020).

30. M. Ohki et al., "Automated processing for flood area detection using ALOS-2 and hydrodynamic simulation data," Remote Sens. 12, 2709 (2020). 
31. U. Soergel, U. Thoennessen, and U. Stilla, "Visibility analysis of man-made objects in SAR images," in 2nd GRSS/ISPRS Joint Workshop "Data Fusion and Remote Sens. Over Urban Areas", Berlin, (2003).

32. D. C. Mason et al., "Flood detection in urban areas using TerraSAR-X," IEEE. Trans. Geosci. Remote Sens. 48(2), 882-894 (2010).

33. D. C. Mason et al., "Near real-time flood detection in urban and rural areas using high resolution synthetic aperture radar images," IEEE. Trans. Geosci. Remote Sens. 50(8), 3041-3052 (2012).

34. D. C. Mason et al., "Detection of flooded urban areas in high resolution synthetic aperture radar images using double scattering," Int. J. Appl. Earth Obs. Geoinf. 28C, 150-159 (2014).

35. D. C. Mason et al., "A robust algorithm for detecting floodwater in urban areas using synthetic aperture radar images," J. Appl. Remote Sens. 12(4), 045011 (2018).

36. M. Tanguy et al., "River flood mapping in urban areas combining RADARSAT-2 and flood return period data," Remote Sens. Environ. 198, 442-459 (2017).

37. L. Pulvirenti et al., "Use of SAR data for detecting floodwater in urban and agricultural areas: the role of interferometric coherence," IEEE Trans. GeoSci. Remote Sens. 54(3), 1532-1544 (2016).

38. M. Chini et al., "Sentinel-1 InSAR coherence to detect floodwater in urban areas: Houston and Hurricane Harvey as a test case," Remote Sens. 11, 107 (2019).

39. Y. Li, S. Martinis, and M. Wieland, "Urban flood mapping with an active self-learning convolutional neural network based on TerraSAR-X intensity and interferometric coherence," ISPRS J. Photogramm. Remote Sens. 152, 178-191 (2019).

40. Y. N. Lin et al., "Urban flood detection with Sentinel-1 multi-temporal synthetic aperture radar (SAR) observations in a Bayesian framework: a case study for Hurricane Matthew," Remote Sens. 11, 1778 (2019).

41. P. Iervolino et al., "Flooding water depth estimation with high-resolution SAR," IEEE Trans. GeoSci. Remote Sens. 53(5), 2295-2307 (2015).

42. M. Chini et al., "A hierarchical split-based approach for parametric thresholding of SAR images: flood inundation as a test case," IEEE Trans. Geosci. Remote Sens. 55, 6975-6988 (2017).

43. L. Giustarini, et al., "Accounting for image uncertainty in SAR-based flood mapping," Int. J. Appl. Earth Obs. Geoinf. 34, 70-77 (2015).

44. R. Guida, A. Iodice, and D. Riccio, "Height retrieval of isolated buildings from single highresolution SAR images," IEEE Trans. Geosci. Remote Sens. 48(7), 2967-2979 (2010).

45. Y. Dong, B. Forster, and C. Ticehurst, "Radar backscatter analysis for urban environments," Int. J. Remote Sens. 18(6), 1351-1364 (1997).

46. G. Franceshetti, A. Iodice, and D. Riccio, "A canonical problem in electromagnetic backscattering from buildings," IEEE Trans. Geosci. Remote Sens. 40(8), 1787-1801 (2002).

47. B. Wessel et al., "Accuracy assessment of the global TanDEM-X Digital Elevation Model with GPS data," ISPRS J. Photogramm. Remote Sens. 139, 171-182 (2018).

48. G. J.-P. Schumann and P. D. Bates, "The need for a high-accuracy open-access global DEM," Front. Earth Sci. 6, 225 (2018).

49. M. Marconcini et al., "Outlining where humans live, the World Settlement Footprint 2015," Nat. Sci. Data 7, 242 (2020).

50. BBC News "Fishlake flooding; fears for village as more rain due," https://www.bbc.co.uk/ news/uk-england-50372839 (2019).

51. River Levels UK, https://riverlevels.uk/levels\#.YAhZ0uj7RPY (2020).

52. WalesOnline, "Pontypridd town centre flooded as river Taff overflows after torrential Storm Dennis downpours," https://www.walesonline.co.uk/news/wales-news/pontypridd-floodstorm-dennis-warning-17756757 (2020).

53. L. S. Davis, "A survey of edge detection techniques," Comput. Graphics Image Process. 4(3), 248-270 (1975).

54. D. C. Mason et al., "Improving the TanDEM-X Digital Terrain Model for flood modelling using flood extents from synthetic aperture radar images," Remote Sens. Environ. 173, 15-28 (2016). 
55. Environment Agency, "Learn more about flood risk," https://flood-warning-information .service.gov.uk/long-term-flood-risk/map (2020).

56. Natural Resources Wales, "Long term flood risk," https://naturalresources.wales/evidenceand-data/maps/long-term-flood-risk/?lang=en (2020).

57. M. Lachaise and T. Fritz, "Update of the interferometric processing algorithms for the Tan-DEM-X high resolution DEMs," in EUSAR 2016; Proc., pp. 1-4 (2016).

58. G. Baier et al., "A non-local InSAR filter for high resolution DEM generation from TandemX interferograms," IEEE Trans. Geosci. Remote Sens. 56(11), 6469-6483 (2018).

59. S. Gopal and B. Mercer, "National and regional scale DEMs created from airborne InSAR," in Proc. EARSEL Symp. Remote Sens. Changing Eur., pp. 188-196 (2009).

60. S. C. Biggs and M. Andrews, "Acceleration of iterative image restoration algorithms," Appl. Opt. 36(8), 1766-1775 (1997).

David C. Mason is a senior research fellow in the Department of Geography and Environmental Science at the University of Reading, UK. He obtained his BSc and PhD degrees in physics from Imperial College, University of London. His current research interest is the use of remote sensing in hydrology, in particular using SAR flood extents for emergency flood relief management and improved flood inundation forecasting, and SAR soil moisture for improved hydrologic modeling.

Sarah L. Dance is a professor of data assimilation at the University of Reading, UK, jointly held in the Department of Mathematics and Statistics and the Department of Meteorology. She completed her PhD in the Division of Applied Mathematics at Brown University, USA, in 2002. She recently codirected the UK NERC Flooding from Intense Rainfall programm and holds an EPSRC Senior Fellowship in Digital Technology for Living with Environmental Change.

Hannah L. Cloke is a professor of hydrology at the University of Reading, UK and guest professor at Uppsala University, Sweden. She obtained her BSc (1999) and PhD degrees (2003) in geography from the University of Bristol, UK. Her current research focuses on the theoretical and practical development of early warning systems for natural hazards, particularly for floods, and disaster risk management, for which she was awarded the Plinius Medal of the European Geosciences Union in 2018. 